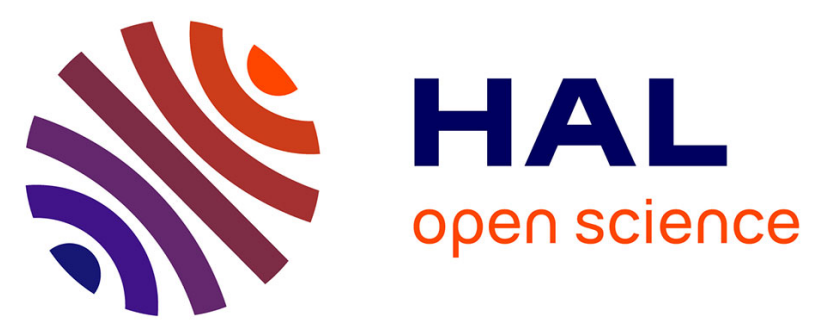

\title{
LumicyanoTM: A new fluorescent cyanoacrylate for a one-step luminescent latent fingermark development
}

Cosimo Prete, Laurent Galmiche, Fifonsi-Gwladys Quenum-Possy-Berry, Clémence Allain, Nicolas Thiburce, Thomas Colard

\section{To cite this version:}

Cosimo Prete, Laurent Galmiche, Fifonsi-Gwladys Quenum-Possy-Berry, Clémence Allain, Nicolas Thiburce, et al.. LumicyanoTM: A new fluorescent cyanoacrylate for a one-step luminescent latent fingermark development. Forensic Science International, 2013, 233, pp.104-112. 10.1016/jforsciint.2013.07.008 . hal-00919009

\section{HAL Id: hal-00919009 \\ https://hal.science/hal-00919009}

Submitted on 16 Dec 2013

HAL is a multi-disciplinary open access archive for the deposit and dissemination of scientific research documents, whether they are published or not. The documents may come from teaching and research institutions in France or abroad, or from public or private research centers.
L'archive ouverte pluridisciplinaire HAL, est destinée au dépôt et à la diffusion de documents scientifiques de niveau recherche, publiés ou non, émanant des établissements d'enseignement et de recherche français ou étrangers, des laboratoires publics ou privés. 


\section{Lumicyano $^{\mathrm{TM}}$ : a new fluorescent cyanoacrylate for a one-step luminescent latent fingermark}

development.

Cosimo PRETE ${ }^{\mathrm{a}^{*}}$, Laurent GALMICHE ${ }^{\mathrm{b}}$, Fifonsi-Gwladys QUENUM-POSSY-BERRY ${ }^{\mathrm{c}^{*}}$, Clémence ALLAIN $^{\mathrm{b}^{*}}$, Nicolas THIBURCE ${ }^{\mathrm{d}}$, Thomas COLARD ${ }^{\mathrm{e}}$

\section{Corresponding author}

Fifonsi-Gwladys QUENUM-POSSY-BERRY

Cosimo PRETE

Clémence ALLAIN

Addresses:

${ }^{a}$ Crime Scene Technology, 2b - 21 Allée du Cercle, 59650 Villeneuve d'Ascq, France.

${ }^{\mathrm{b}}$ PPSM, Institut d'Alembert, ENS Cachan, CNRS, UniverSud, 61 av President Wilson, F-94230 CACHAN, France

${ }^{\mathrm{c}}$ IRCGN Fingerprint Unit, 1 boulevard Théophile Sueur, 93110 Rosny-Sous-Bois, France.

${ }^{\mathrm{d}}$ Compagnie de gendarmerie de La Rochelle, Caserne Duverdier, 121 rue des Gonthières, 17140 Lagord, France/ Université de Lausanne - Ecole des Sciences Criminelles. Batochimie - 1015 Lausanne, Switzerland

${ }^{\text {e } U n i t e ́ ~ d e ~ T a p h o n o m i e ~ m e ́ d i c o-l e ́ g a l e ~ / ~ I . M . L ~(U n i v e r s i t e ́ ~ d e ~ L i l l e ~ 2) ~}$

Corresponding authors

Email address: cosimo.prete@,crimescenetechnology.fr (C. Prete). Tel.: +33 320473307

Email address: fifonsi-gwladys.quenum-possy-berry@gendarmerie.interieur.gouv.fr (F.-G. Quenum-Possy-Berry) Tel.: +33 158665058

Email address: callain@ppsm.ens-cachan.fr (C. Allain). Tel.: +33 147405357. Fax.: +33 147402454 


\section{ACKNOWLEDGEMENTS:}

We warmly thank Pr Pierre Audebert, head of the PPSM research team, who initiated this research subject and supported us with helpful discussions throughout.

We are also greatful for the time the IRCGN fingerprint unit staff spent on the operational evaluation and particularly to the practitioners who assessed the processed fingermarks. 


\begin{abstract}
Latent fingermarks developed by cyanoacrylate fuming often lack contrast; therefore further enhancement is required, such as dye staining. This second step is part of the conventional detection sequences performed by forensics practitioners. Dye-staining or powder dusting aims at improving contrast and at increasing the legibility of details, yet their use may at times be limited. Indeed powder dusting may not be effective due to unexpected adherence to the background, and poor affinity to the cyanoacrylate. In the same way staining processes can dye a whole semi-porous surface or may wash the marks.

To avoid that second step, a new luminescent cyanoacrylate (Lumicyano ${ }^{\mathrm{TM}}$ ) which allows one-step development without changing the fuming chamber settings $\left(80 \%\right.$ humidity rate, $120^{\circ} \mathrm{C}$ fuming temperature) was developed and assessed. This study aimed at comparing Lumicyano ${ }^{\mathrm{TM}}$ to a conventional two-step process. A detailed sensitivity study was conducted on glass slides, as well as the processing of various non-porous and semi-porous substrates, usually considered as problematic for a dye staining step.

The results indicate that Lumicyano ${ }^{\mathrm{TM}}$ detects fingermarks with equal or better sensitivity and ridge details than currently used cyanoacrylate. Secondly in luminescent mode, good ridges clarity and excellent contrast are observed, even if Lumicyano ${ }^{\mathrm{TM}}$ is sometimes less bright than the two-step process. Furthermore, conventional enhancement can still be carried out if needed. As a conclusion, Lumicyano $^{\mathrm{TM}}$ makes it possible to avoid an enhancement step which can be detrimental to further examinations, particularly on rough or semi-porous surfaces.
\end{abstract}

KEYWORDS: Fluorescent cyanoacrylate, latent fingermark, non-porous surfaces, semi-porous substrates, dye staining, Lumicyano.

\title{
1. INTRODUCTION
}

Among the lot of finger mark development techniques reported in the literature (for a review see [1] and references therein), cyanoacrylate fuming is an extremely simple and efficient method described for the first time in the late 1970s, in Japan and slightly later in UK and Canada [2, 3]. Items with potential latent marks are placed in a tightly closed fumigation chamber under $80 \%$ humidity atmosphere and the cyanoacrylate evaporates upon heating at $120^{\circ} \mathrm{C}$ [4]. Although the chemical process is still under debate and not well understood [5-8], the anionic polymerization of cyanoacrylate takes place, in this condition, probably initiated by a variety of compounds contained in the residue constituting the mark, such as amino acids, fatty acids and proteins.. Thus, latent marks are efficiently detected on non-porous and semi-porous substrates as a sticky white material that forms along the papillary ridges. 
However, the main limitation of this technique arises from the white colour taken by the detected fingermarks, which often lacks contrast with the light coloured substrates. Several post-treatments have been proposed to overcome this issue. They consist in dusting the fingermark with coloured or fluorescent dye powders [9], or staining the CA-developed marks with a fluorescent dye solution such as Ardrox [10], Basic Yellow 40, or Rhodamine 6G [11]. However, these post-treatments are time-consuming and sometimes contain carcinogenous compounds. For example, Rhodamine 6G itself is suspected to be carcigenous [12] and Ardrox and Basic Yellow 40 solutions can contain methanol: the use of these fluorescent solutions requires appropriate protection for laboratory workers, such as fume-cupboards, and adequate waste elimination, which are expensive and require space. Moreover, staining treatment with fluorescent dyes is not possible on various substrates, particularly on semi-porous ones. Indeed the staining solution may also stain the background. Finally, on non-porous surfaces, to avoid too a high background reaction, the stain has to be rinsed and fingerprints may be washed away; this rinsing step is also detrimental to electrical equipment which cannot be immersed.

Few studies $[13,14]$ propose staining methods based on the sublimation of a fluorescent dye. These methods are usually difficult to use because of the high temperature needed to obtain the sublimation of the dye or because of the high exposition time of the cyanoacrylate-fumed latent fingerprint to the dye vapour-phase. In both cases, these post-treatments are also time-consuming.

Considering all these limitations, the development of a one-step fluorescent cyanoacrylate method has been a topic of outstanding interest for several years [15, 16]. Hahn and Ramotowski [17] have recently described such a fluorescent cyanoacrylate which requires a very high temperature $\left(230^{\circ} \mathrm{C}\right)$ for fumigation. This severely limits the application of this new product, since it requires a modification of the fuming chambers and since there is a risk, at such a high temperature, of cyanoacrylate decomposition to product lethal cyanide gas [18].

We report here the use of a new fluorescent cyanoacrylate, Lumicyano ${ }^{\mathrm{TM}}$, developed by Crime Scene Technology (CST) in association with the Ecole Normale Supérieure (ENS) de Cachan, containing a easily sublimable low-molecular weight fluorophore that allows the one-step fluorescent revelation of latent fingerprints under standard humidity and temperature fumigation conditions $\left(80 \%\right.$ humidity, $\left.120^{\circ} \mathrm{C}\right)$. The fluorescence can be observed either under UV (315$340 \mathrm{~nm})$ or visible $(450-550 \mathrm{~nm})$ intense light irradiation, ensuring a good compatibility with the lightning material available within most police forces.

The quality of this new fingermark development process has been assessed by the French Gendarmerie Forensic Science Institute (IRCGN). First, a detailed comparison with a usual twostep process (cyanoacrylate fuming followed by staining with Basic Yellow 40) has been conducted on glass slides, on fresh as well as on aged fingermarks (up to 4 weeks). Then, the techniques have been applied to a variety of non-porous and some semi-porous substrates. 


\section{MATERIALS AND METHODS}

\subsection{Spectroscopy}

Spectroscopic measurements were done in order to show that absorption and emission spectra were scarcely changed by the different states of the fluorophore, and above all, to provide practitioners with useful data to choose accurate light source and filters (luminescence mode).

UV-Vis absorption spectra were recorded using an Agilent Cary 5000 spectrophotometer. Fluorescence emission spectra were recorded using a Horiba Jobin-Yvon Fluorolog-3 spectrofluorimeter. For measurements in solution, a right angle configuration was used and optical density was adjusted below 0.1 to avoid reabsorption artifacts. For solid state measurements (thin films and fingermarks), a front-face configuration was used. Fluorescence quantum yield was measured using Rhodamine $6 \mathrm{G}$ in ethanol as a reference.

\subsection{Physical examination}

To investigate in details the quality of the polymerization process, physical examination has been undergone with two devices: a QUANTA 400 Environmental Scanning Electron Microscope (ESEM) made by FEI and a digital microscope (VHX 2000 manufactured by Keyence), equipped with lens Z100 or Z20. Samples were illuminated by a Vilber-Lourmat UV lamp $(\mathrm{P}=6 \mathrm{~W}$, $\left.\lambda_{\text {max }}=312 \mathrm{~nm}\right)$.

\subsection{Samples preparation}

\subsubsection{Surfaces}

Different substrates were used during this study. To compare the Lumicyano ${ }^{\mathrm{TM}}$ efficiency and sensitivity with the conventional sequence (cyanoacrylate followed by dye staining), "cut edge frosted" microscope slides provided by VWR were used ${ }^{1}$. The slides were used directly after being picked out of their pack.

In a second stage, to check the Lumicyano ${ }^{\mathrm{TM}}$ versatility, miscellaneous types of items were used.

- Non-porous surfaces:

- black trash bags in polyethylene,

- clingwraps for fridge and microwave use, supplied by Systeme U.

- Coca Cola (Olympic Games edition) and Canada dry cans.

- Semi-porous surfaces:

○ photo paper for printer DS80 manufactured for the media set $n^{\circ} \mathrm{DM} 81280$ by Dai Nippon Printing Co. Ltd,

\footnotetext{
${ }^{1}$ During the test period, we run out of slides, and as the new slides sent by VWR were different and lightly UVluminescent, we change to "ground color frosted white" by VWR which made no significant difference with the first ones-.
} 
- Camel cigarette packs,

$\circ$ postcards $n^{\circ} 5227$ printed by Hüber edition.

This last step aims at illustrating the ability of Lumicyano ${ }^{\mathrm{TM}}$ to be easily used on "operational" cases under normal practical environmental conditions.

\subsubsection{Fingermarks}

For the first part of the study, as the comparison should be the most controlled and reproducible as possible in our lab, participants were asked to wash and dry their hands, and then waited for 20 minutes without touching anything. Before depositing marks on microscope slides, they were asked to pass each hand on another in order to evenly distribute secretions.

During the second part of the study (processing of miscellaneous surfaces), eccrine, sebaceous, and uncontrolled marks were deposited on the various surfaces. As for sebaceous marks, participants were asked not to put any cream or product on their face before coming to work. Then they performed the same process as for eccrine marks but after having dried their hands, they wipe the wings of their nose with their thumbs.

\subsubsection{Depletion series and donors}

To compare the two processes, nine donors ( 7 male and 2 female of different ages) were chosen for the intervariability of their fingermark quality. A ranking of donors, based on conventional cyanoacrylate fuming developments on eccrine marks, has been made. Donor A has been judged as being the best one and donor I as being the worst one.

Several depleted marks were planted successively. By doing so, the quantity of secretion decreases from the first to the last marks. Prior to this study, tests have been carried out to choose an accurate number of marks for the depletion series. Four donors (included into the study) deposited 10 times a mark on a slide pausing three seconds. For two of them (considered as "bad donors") there were no significant prints revealed after the third one (included). As the quality of fingermarks is dependent on numerous factors (donors' health, contact force and duration...), we chose not to go beyond the third depletion, thus acknowledging the problem of depletion discussed in other studies [19]. With this methodology, each series consists of 27 marks (9 donors giving 3 fingermarks each).

During the second part of the study, no depletion was used but only two fingermarks were planted because the first one might be too charged with secretions.

\subsubsection{Deposition protocol}

Two microscope slides were put side by side and donors asked to leave their fingermarks at the junction of the two slides. Therefore the two halves of the mark can be processed separately without other handlings. Donors let their finger two seconds at the junction. 
For the study on miscellaneous surfaces, each sample was also cut into two before the fingermarks were left.

\subsubsection{Ageing}

Time and ageing conditions have an effect on cyanoacrylate fuming efficiency [7]. To check the Lumicyano $^{\mathrm{TM}}$ ability to detect fresh and old marks, three ageing times were chosen (i.e., a day, a week and 4 weeks), this period choice being inspired of Kent's recommendations [20]. All the depletion series were stored in a ventilated closet at room temperature in a dark space. Rubbing is avoided by putting the slides on trays and placing the trays on the upper shelves of the closet, humidity is not accurately controlled (the variation is under the environmental condition of our laboratory), but outdoor major variations are contained thanks to the ventilation system; thus marks would undergo a constant dry. This methodology provided us 81 marks ( 3 series of 27 marks).

Secondly, on miscellaneous surfaces deposited marks were treated within two days after deposition.

\subsection{Processing}

\subsubsection{Cyanoacrylate fuming}

Two kinds of processes were compared:

- Lumicyano ${ }^{\mathrm{TM}}$ is produced by Crime Scene Technology (France). This red liquid is composed of $99 \%$ cyanoacrylate and $1 \%$ fluorophore.

- Cyanobloom (low viscosity) purchased from Foster + Freeman, followed by enhancement.

The cyanoacrylate fuming cabinet is the MVC 5000 (2003 model version 6.2b), made by Mason Vactron and supplied by Foster + Freeman. In this study, the fuming time was of 20 minutes. Parameters are those commonly advocated and in accordance with our accredited protocol under ISO 17025: a maximum of $80 \%$ humidity rate and $120^{\circ} \mathrm{C}$ fuming temperature $[21,22]$.

For a given ageing period, all depletion series left halves are processed with $3.5 \mathrm{~g}$ of Cyanobloom. Afterwards, the chamber is let wide open to cool down the system at room temperature. The second halves are processed the same way with $3.5 \mathrm{~g}$ of Lumicyano ${ }^{\mathrm{TM}}$. Slides are hanged, always in the same order, on metal bars at the chamber upper level.

\subsubsection{Image recording}

After having being processed, the halves of each fingermark were gathered and photographed under white light (both in the first and the second part of the study).

Afterwards halves treated with Lumicyano ${ }^{\mathrm{TM}}$ are lit under UV light $(312 \mathrm{~nm})$, photos were taken within 4 hours after the fumigation. 


\subsubsection{Enhancement}

After at least 24 hours drying in a ventilated chamber, slides processed with cyanoacrylate (Cyanobloom or Lumicyano ${ }^{\mathrm{TM}}$ ) were dyed with Basic Yellow 40 dissolved in methanol (1.5 $\mathrm{g}$ for $1 \mathrm{~L}$ methanol [22]). Slides are stained by drop-casting a BY40 solution on the mark, then washed with distilled water, and finally let to dry at room temperature in a ventilation box during a few minutes (until the rinsing water evaporates).

Concerning tests on miscellaneous surfaces, enhancement has also been processed with YELLOWescent $^{\mathrm{TM}}$ latent print powder manufactured by SIRCHIE, or MAGNETA FLAKETM fingerprint powder manufactured by CSI Ltd, depending on surfaces type and colour.

\subsection{Imaging}

UV light is provided by:

- a gas-discharged lamps (provided by Consort) $30 \mathrm{~W}$ at $312 \mathrm{~nm}$ wavelength, at $5 \mathrm{~cm}$ from the slides in the first part of the study.

- a SUPERLITE 400 made by Lumatec ${ }^{\circledR}$, at $320 \mathrm{~nm}$ to $400 \mathrm{~nm}$ (filterwheel on position $\mathrm{Nr}$, $1.8 \mathrm{~W} / \mathrm{cm}^{2}$ ) to light the miscellaneous surfaces in the second part of the study.

White and blue $\left(445 \mathrm{~nm}\right.$ ) lights are provided by a CrimeScope ${ }^{\circledR}$ CS-16-500 (manufactured by SPEX forensics, HORIBA/Jobin\&Yvon, 2006 model) at an angle of $45^{\circ}, 25 \mathrm{~cm}$ away from the slides.

In the first part of the study, pictures are taken with a NIKON D300 camera and an AF-S VR MicroNikkor $105 \mathrm{~mm} \mathrm{f} / 2.8 \mathrm{G}$ IF-ED lens, always at the same distance from the slides $(42 \mathrm{~cm})$.

In the second part of the study, the former camera and also a NIKON D800 were used with the same lens.

Camera white balance set up was chosen in order to get a picture colour (through a UV or the Tiffen $\mathrm{n}^{\circ} 15$, deep yellow filters) similar to what is seen by eyes only protected by (respectively) UV or yellow goggles provided with the Crimescope. Other camera setups were chosen to get the best contrast. Contrast is not further improved by image processing, but only by taking in photo fluorescent marks through a UV or the yellow filter.

\subsection{Scoring}

Four fingerprint examiners from IRCGN - but not included in the study processes - were asked to compare the two cyanoacrylate processes.

Three comparison files were created, inspired by the work of Wilkinson and Misner [23]:

- In file I, half-fingermarks developed with Lumicyano ${ }^{\mathrm{TM}}$ are compared with halffingermarks developed with Cyanobloom, both photographed under white light. 
- In file II, half-fingermarks developed with Lumicyano ${ }^{\mathrm{TM}}$ and photographed under UV light are compared with half-fingermarks developed with Cyanobloom + BY40 and photographed under blue light.

- In file III, half-fingermarks developed with Lumicyano ${ }^{\mathrm{TM}}+$ BY40 are compared with halffingermarks developed with Cyanobloom + BY40, both photographed under blue light.

For each series, technicians were provided with an instruction sheet and were asked to assess fingerprints about 3 evaluation criteria: contrast (meaning the ability of the fingerprint ridges to part with the background), ridges continuity (meaning the possibility of watching unbroken ridges and the ridges flow), level of details (meaning the possibility of watching second (minutiae) and even third level details (pores and ridge edges)).

Still to avoid bias, assessors gave a letter to each mark (for each mark a particular half is pointed to):

- A, if the half pointed to is judged to give the best result;

- $\mathrm{B}$, if the half pointed is judged to give the lower result;

- or $\mathrm{C}$ if they cannot decide in between;

without knowing which half is being processed by Lumicyano.

Those letters are collected from the assessors and are related to a score depending on how is the mark positioned $\left(A=1 \quad B=-1\right.$ if dealing with Lumicyano ${ }^{\mathrm{TM}}, \mathrm{A}=-1$ or $\mathrm{B}=1$ otherwise, $\mathrm{C}=0$ ).

Finally, all marks are added and averaged by the number of practitioners and fingerprints. Two thresholds were set up: the first one for results slightly more or less optimal (the same on both parts of equality) and the second for results more or less optimal (the same on both parts of equality).

Results are summarized in tables 2, 3 and 4.

\section{RESULTS AND DISCUSSION}

\subsection{Spectroscopy}

The UV-visible absorption spectrum of the fluorophore contained in Lumicyano ${ }^{\mathrm{TM}}$ was recorded in acetonitrile solution (Figure 1). It shows two absorption bands: one, intense, in the UV range at $326 \mathrm{~nm}$ and a weaker transition in the visible range $(511 \mathrm{~nm})$. The fluorescence emission spectrum of the fluorophore in acetonitrile solution shows a broad and intense (quantum yield $=0.27$ ) emission band centred at $562 \mathrm{~nm}$ (yellow). 


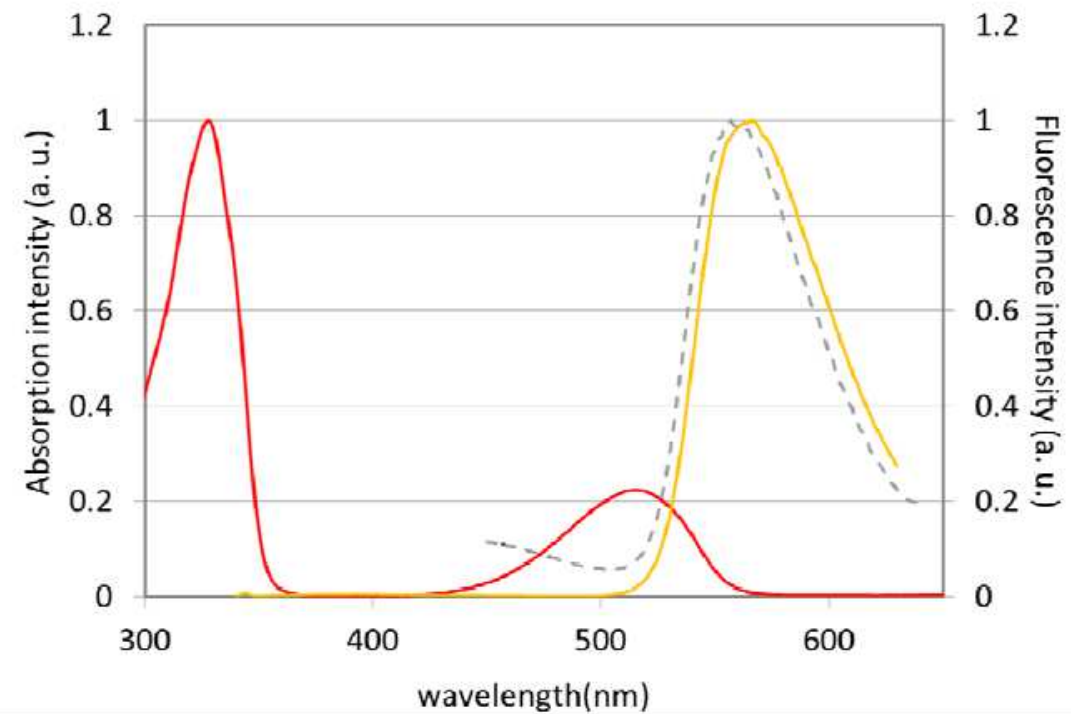

Figure 1: Normalized absorption spectrum (red curves, left scale) and normalized emission spectrum (yellow curves, right scale) of the fluorophore in acetonitrile solution. Normalized emission spectrum of a fingermark fumigated using Lumicyano ${ }^{\mathrm{TM}}$ (dashed black line, right scale).

The same absorption and fluorescence spectra were recorded in the solid state on a polymerized Lumicyano $^{\mathrm{TM}}$ film obtained by sticking 2 microscope slides with 2 drops of Lumicyano ${ }^{\mathrm{TM}}$. The spectra in solution and in the solid state are very similar, which indicates that the structure of the fluorophore is not modified during the polymerization process.

A microscope slide coated with grease and a latent fingermark left on a microscope slide have been fumigated with Lumicyano ${ }^{\mathrm{TM}}$ in the standard conditions. In both cases, the polycyanoacrylate deposit is opaque and it is not possible to record absorption spectra. We only recorded fluorescence spectra (Figure 1). No spectral difference appears between the homogeneous films obtained from the grease coated microscope slide and the processed fingermark. In both cases, the fluorescence spectrum is similar to those obtained for the fluorophore in acetonitrile solution and for the fluorophore in a polymerized Lumicyano ${ }^{\mathrm{TM}}$ film obtained without sublimation. This confirms again that the structure of the fluorophore is not modified during the sublimation process. Table 1 summarizes the absorption maxima and fluorescence emission maxima for the studied samples. The small variation in the maximum values can easily be explained by a change of the local environment of the fluorophore and especially by a modification of the local polarity[24].

\begin{tabular}{|c|c|c|}
\hline & Absorption wavelength (nm) & Emission wavelength (nm) \\
\hline Fluorophore in acetonitrile solution & $326 / 511$ & 562 \\
\hline Lumicyano $^{\mathrm{TM}}$ film & $328 / 515$ & 566 \\
\hline Lumicyano $^{\mathrm{TM}}$ fumigated film & - & 557 \\
\hline Lumicyano $^{\mathrm{TM}}$ fumigated fingerprint & - & 557 \\
\hline
\end{tabular}

Table 1: Absorption and emission wavelengths of the Lumicyano ${ }^{\mathrm{TM}}$ fluorophore in different conditions and states. 


\subsection{Morphology of the polymer}

\subsubsection{SEM Pictures}

To investigate in details the quality of the polymerization process, fingermarks detected using the Lumicyano $^{\mathrm{TM}}$ were imaged using scanning electron microscopy. SEM pictures show a very high and homogeneous concentration of noodle-type polymer on the ridges (Figure 2a) and a very low polymer development between the ridges (Figure 2b). Several studies [8, 21, 25-27] have shown that the noodle-type polymerization is associated with a good macroscopic development of the latent fingermark. This kind of polymer corresponds to a maximized contrast between the ridges and the background, and it has been demonstrated that it is obtained for a humidity rate close to 80 $\%$ [21]. Doiphode et al. [28] have shown that heating the monomer at low temperature (upper than $100^{\circ} \mathrm{C}$ but lower than $180^{\circ} \mathrm{C}$ ) results in a low monomer concentration in the vapour phase, small monomer droplets being formed in the vapour. They suggest that polycyanoacrylate fibres grow from tiny spots on the substrate where water molecules and polymerization initiators are present according to a vapour-liquid-solid (VLS) process. In such a process, the droplet having initiated the polymerization is gradually carried to the tip of the polymer fibre during his growth. A monomer molecule coming in contact with the fibre tip is quickly polymerized in the presence of water, while the monomer molecule coming on the side of the fibre polymerizes more slowly. The use of the Lumicyano $^{\mathrm{TM}}$ in the standard conditions of fumigation $\left(80 \%\right.$ humidity, $\left.120^{\circ} \mathrm{C}\right)$ leads to the formation of the expected noodle-type polymer fibre. This shows that the fluorophore does not disturb the VLS process.

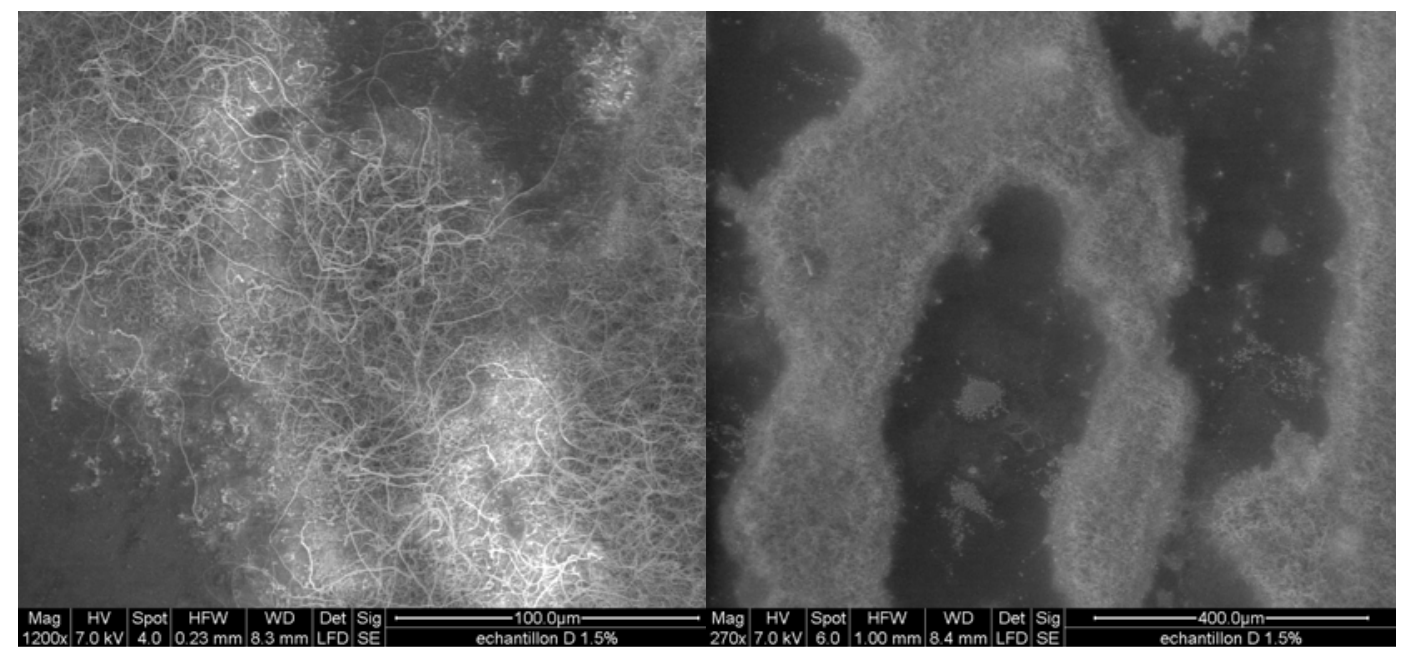

Figure 2: SEM pictures of a latent fingerprint revealed with Lumicyano ${ }^{\mathrm{TM}}$. Magnitude 1200x (a), 270x (b)

\subsubsection{Magnified fluorescent pictures}

Fingermarks developed using the Lumicyano ${ }^{\mathrm{TM}}$ were examined under UV illumination using a digital optical microscope in order to obtain magnified fluorescence pictures of the ridges. An excellent contrast can be observed (Figure 3a), with a perfect co-deposition of the fluorescent dye 
and the polymer of cyanoacrylate, ensuring an adequate signal-to-noise ratio (contrary to what is generally observed with post-staining treatments using fluorescent dyes in solutions). Each polymer fiber is fluorescent, indicating that the polymer and the fluorophore are intimately linked (Figure 3b). This strong affinity between the polymer and the fluorophore leads to a strong selectivity of the deposit of fluorophore which can occur everywhere the polymer is present and only on the polymer.

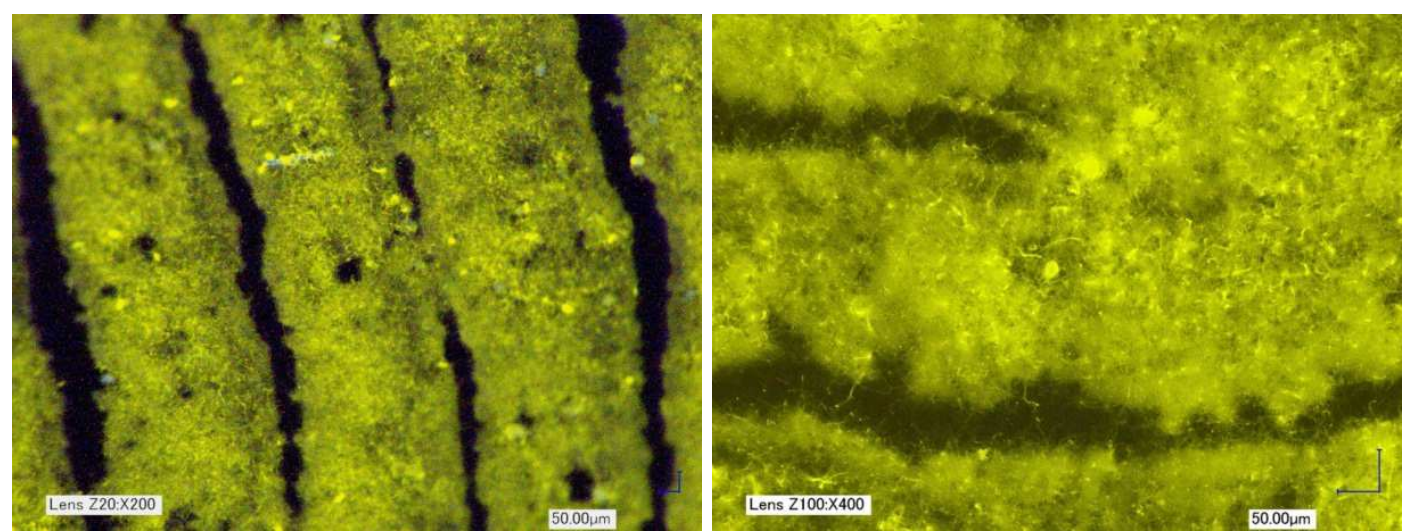

Figure 3: Magnified fluorescent pictures of a latent fingermark detected using the Lumicyano ${ }^{\mathrm{TM}}$, observed under UV light (312 nm). (a) x200, (b) x400.

\subsection{Sensitivity of the Lumicyano ${ }^{\mathrm{TM}}$}

In preliminary tests, different amounts of cyanoacrylate $(2.5 \mathrm{~g}, 3 \mathrm{~g}, 3.5 \mathrm{~g}, 4 \mathrm{~g}$ and $4.5 \mathrm{~g})$ were tested. $3.5 \mathrm{~g}$ was chosen as the most adapted quantity, but good results were also obtained with the $4 \mathrm{~g}$ recommended by Foster + Freeman.

It has been observed that if the Lumicyano ${ }^{\mathrm{TM}}$ fuming process is stopped before the whole glue was fumed, a strongly coloured cyanoacrylate is left in the fuming cup and the detected fingermark appears far less luminescent than it should be. As a consequence, it is recommended to evaporate completely the amount of Lumicyano ${ }^{\mathrm{TM}}$ used in a development process. Preliminary results indicate that overexposure (that is to say, ridges fusion due to an excess of cyanoacrylate deposition) seldom occurs with the Lumicyano ${ }^{\mathrm{TM}}$. We suppose this could be related to the high quality (low viscosity) of the cyanoacrylate monomers used in the Lumicyano ${ }^{\mathrm{TM}}$. A detailed study on this topic is under completion in our laboratories. Furthermore, if marks are under-developed, a subsequent treatment with Lumicyano ${ }^{\mathrm{TM}}$ is still possible.

From the results collected from examination under white light (see Figure 4), it can be concluded that the Lumicyano ${ }^{\mathrm{TM}}$ develops fingermarks better than, Cyanobloom for 1 day and 1 week old fingermarks. Besides, development with Lumicyano and Cyanobloom are slightly the same for 4 weeks old fingermarks.

Observation of the marks shows that the "1 day" and "1 week" Cyanobloom-processed marks were slightly overdeveloped compared to the Lumicyano ${ }^{\mathrm{TM}}$ ones, whereas the " 4 weeks" Lumicyanoprocessed marks were very slightly underdeveloped (remember the amount of cyanoacrylate recommended by Foster\&Freeman is up to $4 \mathrm{~g}$, so quantity can be increased to solve that point). 
This can explain the discrepancies between results. Moreover, the gap between developments quality is narrow (see Tables 2 to 4 ) and it has been difficult for technicians to score one "better" than the other.

Anyway, the same amount of cyanoacrylate has been used for all the processes. So, the score of the Lumicyano $^{\mathrm{TM}}$ on "4 weeks" marks may be improved by slightly increasing the amount of Lumicyano.

Overall, Lumicyano ${ }^{\mathrm{TM}}$-processed fingermarks are slightly better defined than Cyanobloomprocessed ones.

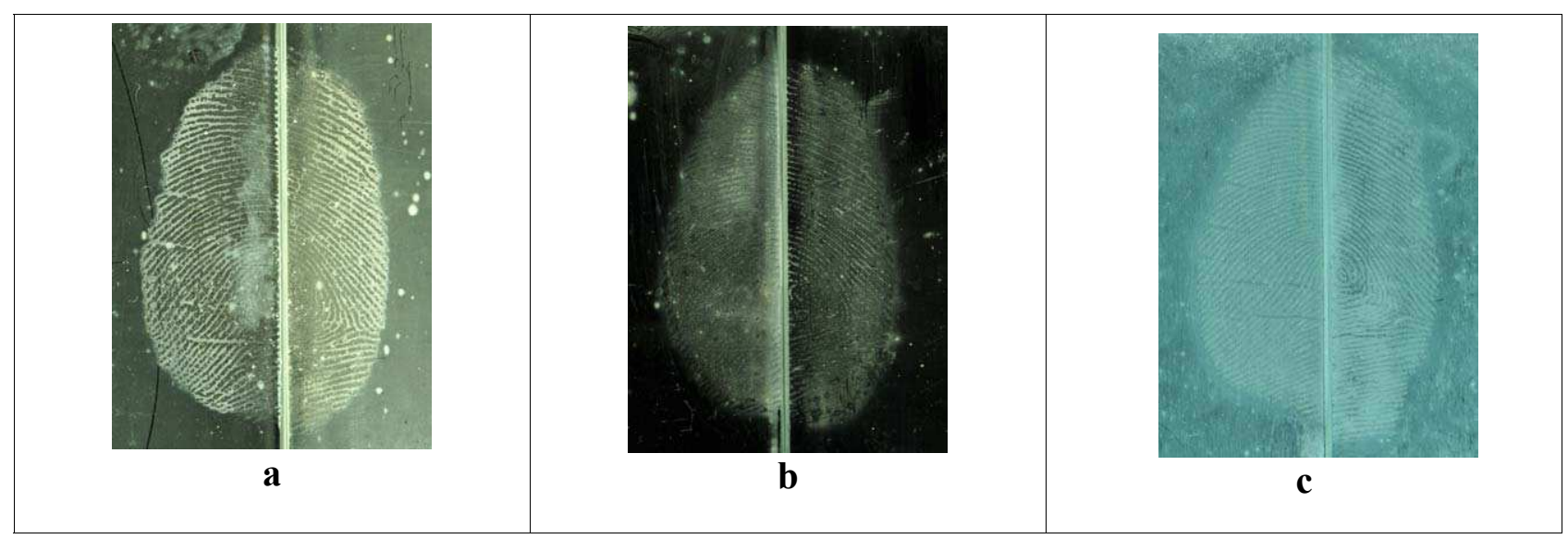

Figure 4: Optical comparison under white light between Cyanobloom (left side) and Lumicyano ${ }^{\mathrm{TM}}$ (right side), for three fingermark ageing periods, i.e., one day (a), one week (b), and four weeks (c).

The pictures of the half-fingermarks processed using the Lumicyano ${ }^{\mathrm{TM}}$, and taken under UV light, show a good contrast. Contrary to Cyanobloom, Lumicyano ${ }^{\mathrm{TM}}$ allows to take fluorescent pictures directly, without any additional staining step.

Examination of the scores given to the comparison file II shows that the contrast obtained with Lumicyano $^{\mathrm{TM}}$ in fluorescence mode is better than the contrast obtained with the half-fingermarks processed using Cyanobloom followed by BY40 staining (see scoring Tables 2 to 4, and see Figure 5 for an example). As for file I, it has been difficult for technicians to score one by comparison with the other regarding the contrast. Nevertheless, when considering the ridges continuity and the ridges detail level, comparison file II shows that BY40 staining enhances the detection process. Indeed, this happens when there are just few polymers (lack of secretions) or when optimized polymerization conditions are not fulfilled. An under-development leads to a weaker fluorescence signal from Lumicyano ${ }^{\mathrm{TM}}$. Consequently, as BY40 is bright and has a strong affinity for cyanoacrylate, the second-step with BY40 staining makes ridges more continuous and brings more ridge details. However, there is still a risk of marks being washed or unwanted background staining. Above all, no digital enhancement has been made on any picture of this study. Indeed, in case of reaction of the background with the dye, the Lumicyano ${ }^{\mathrm{TM}}$ process provides a better signal to noise ratio and digital processing may have improved the Lumicyano ${ }^{\mathrm{TM}}$ results in comparison with the two-step process. 
Finally, comparison file III (see tables 2 to 4) scoring shows that, after an enhancement with BY40, the fingermarks initially processed with the Lumicyano ${ }^{\mathrm{TM}}$ are able to catch up those processed with Cyanobloom. The resulting contrast and ridge definition are increased and may overpass the characteristics of the others. This is consistent with the good quality of the polymerisation observed by SEM.

Table 2: after 1 day

\begin{tabular}{|l|c|c|c|}
\hline \multicolumn{1}{|c|}{ File } & I & II & III \\
\hline Contrast & ++ & + & $=$ \\
\hline Ridges continuity & + & - & $=$ \\
\hline Ridges details level & + & $=$ & \\
\hline
\end{tabular}

Table 3: after 1 week

\begin{tabular}{|l|c|c|c|}
\hline \multicolumn{1}{|c|}{ File } & I & II & III \\
\hline Contrast & ++ & + & ++ \\
\hline Ridges continuity & ++ & - & ++ \\
\hline Ridges details level & + & - & + \\
\hline
\end{tabular}

Table 4: after 4 weeks

\begin{tabular}{|l|c|c|c|}
\hline \multicolumn{1}{|c|}{ File } & I & II & III \\
\hline Contrast & $=$ & - & $=$ \\
\hline Ridges continuity & $=$ & - & - \\
\hline Ridges details level & - & - & \\
\hline
\end{tabular}

Tables 2, 3, and 4: Results of the comparison made by practitioners through three ageing times of the latent fingerprints ( 1 day, 1 week, 4 weeks). Results are means of marks given by 4 practioners on 27 fingermarks and are expressed on a verbal scale:

$\mathrm{I}=$ Lumicyano $^{\mathrm{TM}}$ vs. Cyanobloom, in visible light

$\mathrm{II}=$ Lumicyano $^{\mathrm{TM}}$ in UV vs. (Cyanobloom + BY40 at $445 \mathrm{~nm}$ ), and

$\mathrm{III}=\left(\right.$ Lumicyano $^{\mathrm{TM}}+\mathrm{BY} 40$ at $\left.445 \mathrm{~nm}\right)$ vs. $($ Cyanobloom + BY40 at $445 \mathrm{~nm})$; $\left(++\right.$ means Lumicyano ${ }^{\mathrm{TM}}$ is more optimal than the two-step process.

+ means Lumicyano ${ }^{\mathrm{TM}}$ is slightly more optimal than the two-step process.

$=$ means the two treatments are almost equivalent (less than a ninth of the points is won by one of the treatment).

- means the two-step process is slightly more optimal than Lumicyano ${ }^{\mathrm{TM}}$.

- - means the two-step process is more optimal than Lumicyano ${ }^{\mathrm{TM}}$ ) 


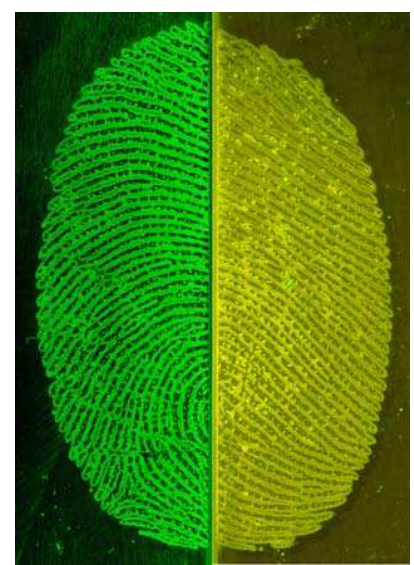

Figure 5: Optical comparison of Cyanobloom+BY40 under blue light: $445 \mathrm{~nm}$ and deep yellow filter (left side), with the one-step Lumicyano ${ }^{\mathrm{TM}}$ fumigation under UV light and deep yellow filter (right side) .

Treatments were undergone on the same on day old fingermark.

\subsection{Fading}

The fluorescence of the Lumicyano ${ }^{\mathrm{TM}}$-processed marks decreases after some time, which depends on the environmental conditions (humidity, temperature) and also strongly on the substrate. For example, fading is fast on glass substrates (see figure 6) but ongoing experiments show that some fingermarks developed on aluminium foil are still fluorescent after several months. As a general rule, observation or photography of the fingerprints should be performed within the first hours.

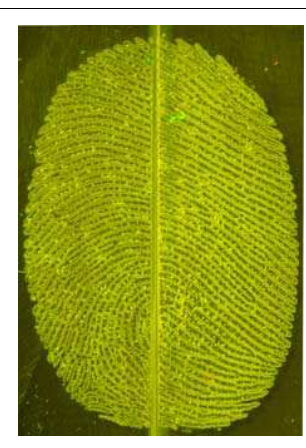

$\mathbf{a}$

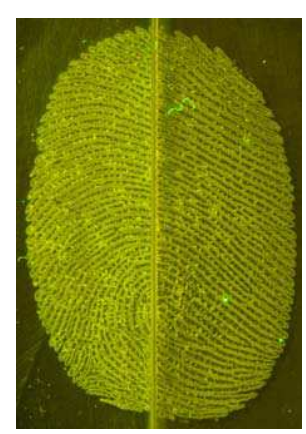

$\mathbf{b}$

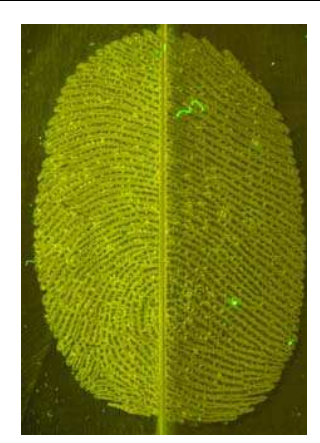

c

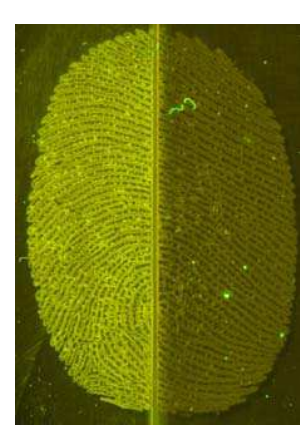

d

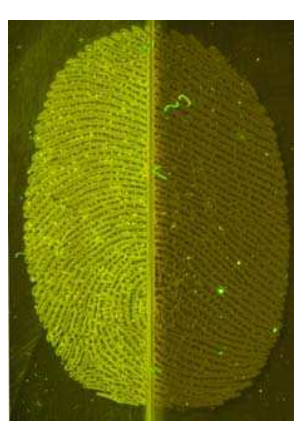

e

Figure 6: Illustration of the luminescence fading on glass slides, for one day old fingermarks revealed by Lumicyano $^{\mathrm{TM}}$. Left side: picture taken just after treatment. Right side pictures taken after 0 (a), 2 (b), 6 (c), 24 (d) and 48 (e) hours.

\subsection{Results on miscellaneous surfaces}

On non-porous surfaces, such as white plastic bags, clingwraps, etc., an enhancement step is often required when dealing with conventional cyanoacrylate fuming. The point is that detected fingermarks are likely to be washed away on that kind of surfaces when the dye is rinsed or are likely to be wiped away by the brush when powder is applied.

No real scoring has been possible given the insufficient number of processed fingermarks in this part of the experiments. Nevertheless, one main observation can be made: when the Lumicyano ${ }^{\mathrm{TM}}$ fuming has sufficiently developed the fingermarks, the fluorescence is high enough to avoid 
staining and give sufficient contrast. If the fluorescence is not satisfactory, a subsequent enhancement process is still possible, in a similar way to any non-fluorescent cyanoacrylate.

Concerning semi-porous surfaces such as postcards, glossy photo paper or cigarette packs, the problem is dye-staining generally results in the staining of the whole item. Thus powdering is required and still may wipe away the fingerprint.

We came to the same conclusions as for difficult non-porous surfaces: when cyanoacrylate fuming has sufficiently developed the fingermarks, fluorescence is bright enough and gives a very good contrast (contrary to Cyanobloom alone) without any risk of detail loss (contrary to Cyanobloom + powder).

It must also be noticed, that Lumicyano ${ }^{\mathrm{TM}}$ has a second absorption peak between $450 \mathrm{~nm}$ and $550 \mathrm{~nm}$ (515 nm centred, see figure 1). A green light combined with orange google and filter could thus be used, but the absorption peak is five times lower than the UV one. However, the use of a green light (for example a green LASER “Tracer” from Coherent and its associated orange bandpass filter) is an alternative for surfaces with a high UV response. Hence with white glossy photopaper, laser illumination makes it possible to photograph prints with a very good contrast without any further enhancement, and the results are far better than after powder dusting (see Figure 7).
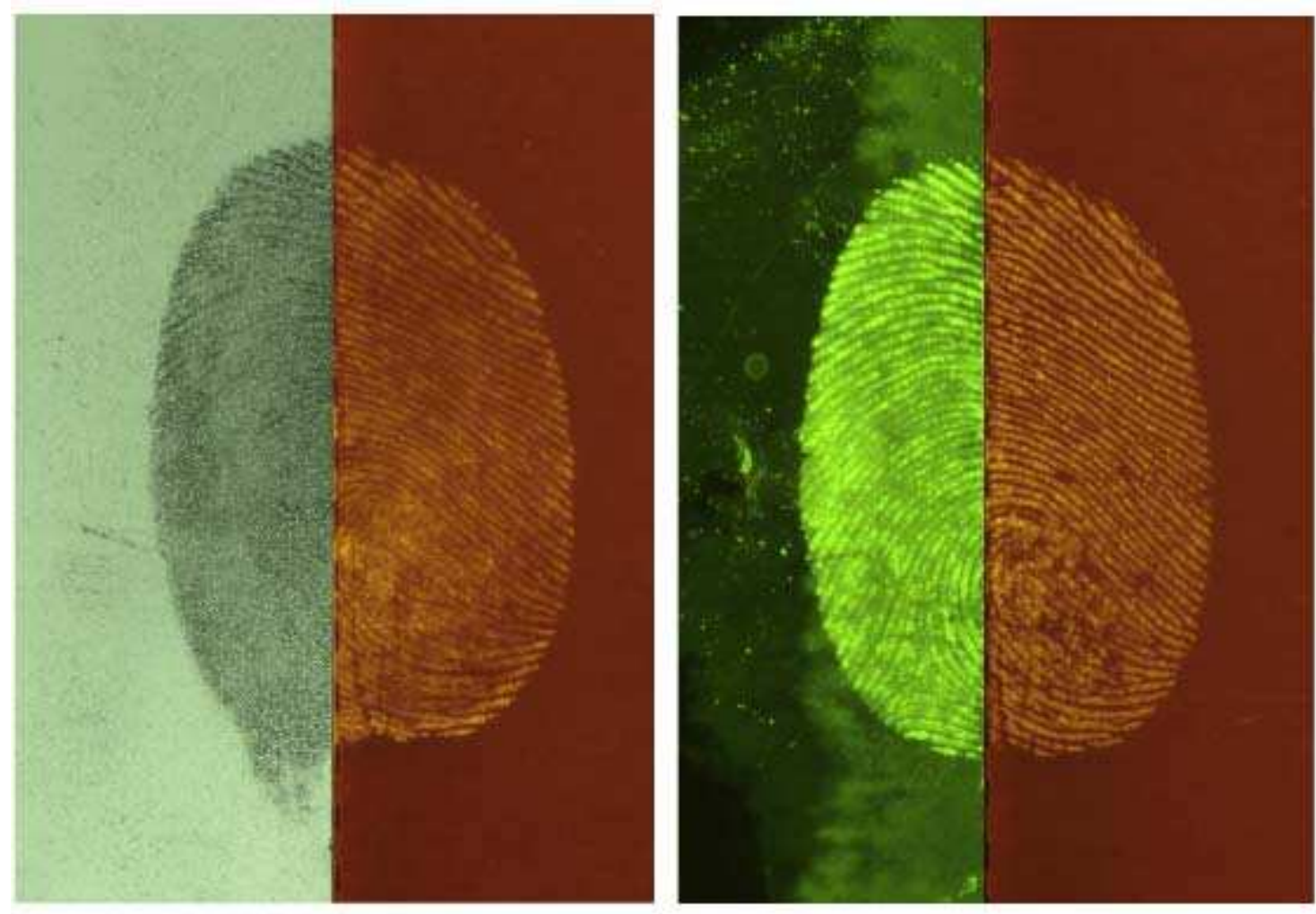

Figure 7: Comparison of development on a piece of white glossy photo paper: (Cyanobloom + MAGNETA FLAKE $^{\mathrm{TM}}$ powder) vs Lumicyano ${ }^{\mathrm{TM}}$ under green light (Laser 532nm) (a), (Cyanobloom+ BY40 under blue light: $445 \mathrm{~nm}$ and deep yellow filter) vs. Lumicyano ${ }^{\mathrm{TM}}$ under green light (Laser 532nm) (b) 
This study has shown that Lumicyano ${ }^{\mathrm{TM}}$ is a one-step fluorescent cyanoacrylate able to develop fingermarks on various surfaces. It appears much easier to use in a forensic laboratory than the other fluorescent cyanoacrylate described in the literature, especially because it has been designed for a use under standard fumigation conditions $\left(120^{\circ} \mathrm{C}, 80 \%\right.$ humidity $)$. This means that health and safety issues arising from the heating of cyanoacrylate at high temperatures are avoided, and that no modification of the fumigation chamber is required. Most forensic laboratories could consequently choose to use the Lumicyano ${ }^{\mathrm{TM}}$ without any modification of their equipment or additional cost.

The detailed comparative examination presented in this study shows that Lumicyano ${ }^{\mathrm{TM}}$ makes it possible to develop fingermarks with a quality equivalent or better compared to the conventional, non-fluorescent, cyanoacrylate (examination under white light). The luminescent signal provided by the Lumicyano ${ }^{\mathrm{TM}}$ allows obtaining readily fluorescent marks that present a good contrast; the signal is sometimes less intense than the one provided by a two-step process (cyanoacrylate fuming followed by enhancement with the fluorescent dye BY40), especially in the case of poorlydeveloped fingermarks. Nevertheless, in such a case, the Lumicyano ${ }^{\mathrm{TM}}$ process provides a better signal to noise ratio and digital processing including new forensics light sources may improve the Lumicyano $^{\mathrm{TM}}$. Furthermore, this study has shown that further enhancement with a fluorescent dye is possible. Indeed, the Lumicyano ${ }^{\mathrm{TM}}$ process can be introduced in a usual two-step sequence with a higher development quality. In addition, this study has shown that Lumicyano ${ }^{\mathrm{TM}}$ allows the development of fluorescent fingermarks on a variety of non-porous and semi-porous surfaces for which the two-step sequence is often problematic. In conclusion, Lumicyano ${ }^{\mathrm{TM}}$ appears to be a new tool for the forensic practitioners, which can provide luminescent fingermarks in one step on a variety of surfaces, and which can be used in a usual two-step sequence if needed.

Further studies are in progress to test the Lumicyano ${ }^{\mathrm{TM}}$ on other problematic surfaces, such as cars or human skin and to improve the fluorescence signal, either by modification of the fluorophore or by making several developments on one item without overdevelopment of the fingerprint. Finally, a study has been performed to assess Lumicyano ${ }^{\mathrm{TM}}$ compatibility with DNA analysis. Results of this study will soon be submitted for publication.

\section{References}

[1] S. M. Bleay, V. G. Sears, H. L. Bandey, A. P. Gibson, V. J. Bowman, R. Downham, L. Fitzgerald and T. Ciuksza, Fingerprint Source Book, Home Office Center for Applied Science Technology (CAST), 2012, [Online] https://www.gov.uk/government/publications/fingerprint-source-book

[2] B. Yamashita and M. French, Latent print development, in: The Fingerprint sourcebook, National Institute of Justice, 1-67, 2011, [Online] (Chapter 7, http://www.ncjrs.gov/pdffiles1/nij/225327.pdf)

[3] E. German, Cyanoacrylate (Superglue) Fuming Tips [Online] http://onin.com/fp/cyanoho.html\#Discovery_Timeline

[4] S. M. Bleay, V. G. Sears, H. L. Bandey, A. P. Gibson, V. J. Bowman, R. Downham, L. Fitzgerald and T. Ciuksza, Finger mark development techniques within scope of ISO 17025, in: Fingerprint Source Book, Home Office Centre for
Applied
Science
and Technology
(CAST), 2012, pp.
233-289
[Online]
(Chapter 3, 
http://www.homeoffice.gov.uk/publications/science/cast/crime-investigation/fingerprint-source-book-2012/fsb-chap3sec1 to3-development?view=Binary).

[5] P. Czekanski, M. Fasola and J. Allison, A mechanistic model for the superglue fuming of latent fingerprints, J Forensic Sci, 51 (2006) 1323-1328

[6] S. P. Wargacki, L. A. Lewis and M. D. Dadmun, Understanding the chemistry of the development of latent fingerprints by superglue fuming, J Forensic Sci, 52 (2007) 1057-1062

[7] S. P. Wargacki, L. A. Lewis and M. D. Dadmun, Enhancing the quality of aged latent fingerprints developed by superglue fuming: loss and replenishment of initiator, J Forensic Sci, 53 (2008) 1138-1144

[8] N. Thiburce, A. Becue, C. Champod and F. Crispino, Design of a Control Slide for Cyanoacrylate Polymerization: Application to the CA-Bluestar Sequence, J. Forensic Ident, 61 (2011) 233-249

[9] L. Liu, Z. Zhang, L. Zhang and Y. Zhai, The effectiveness of strong afterglow phosphor powder in the detection of fingermarks, Forensic Science International, 183 (2009) 45-49

[10] M. M. Mc Carthy, Evaluation of ARDROX as a luminescent stain for cyanoacrylate processed latent impression, $\mathrm{J}$ Forensic Ident, 40 (1990) 75-80

[11] W. D. Mazella, Additional study of cyanoacrylate stains, J Forensic Ident, 45 (1995) 5-18

[12] Rhodamine 6G, National Toxicology Program, (2012), [Online] http://ntp.niehs.nih.gov/go/TS-10052-G

[13] S.-I. Morimoto, A. Kaminogo and T. Hirano, A new method to enhance visualization of latent fingermarks by sublimating dyes, and its practical use with a combination of cyanoacrylate fuming, Forensic Sci.. Int., 97 (1998) 101108

[14] M. Takatsu, O. Shimoda and H. Teranishi, Vapor-phase Staining of Cyanoacrylate-Fumed Latent Fingerprints Using p-Dimethylaminobenzaldehyde, JForensic Sci., 57 (2012) 515-520

[15] D. E. Weaver and E. J. Clary, One-step fluorescent cyanoacrylate fingerprint development technology, J Forensic Ident, 43 (1993) 481-492

[16] M. Spring, L. Gros and W. Deinet, Visualisation of latent fingerprints with cyanoacrylates, Secondary Visualisation of latent fingerprints with cyanoacrylates, University of Idstein Commisioned by the Bundeskriminalamt Wiesbaden, Bundeskriminalamt, Wiesbaden KI2, (December 1995)

[17] W. Hahn and R. Ramotowski, Evaluation of a Novel One-Step Fluorescent Cyanoacrylate Fuming Process for Latent Print Visualization, JForensic Ident, 62 (2012) 279-298

[18] T. C. Fung, K. Grimwood, R. Shimmon, X. Spindler, P. Maynard, C. Lennard and C. Roux, Investigation of hydrogen cyanide generation from the cyanoacrylate fuming process used for latent fingermark detection, Forensic Sci. Int., 212 (2011) 143-149

[19] S. Fieldhouse, Consistency and reproducibility in fingermark deposition, Forensic Sci. Int., 207 (2011) 96-100

[20] T. Kent, Standardzing Protocols for Fingerprint Reagent Testing, J. Forensic Ident, 60 (2010) 371-379

[21] M. Paine, H. L. Bandey, S. M. Bleay and H. Willson, The effect of relative humidity on the effectiveness of the cyanoacrylate fuming process for fingermark development and on the microstructure of the developed marks, Forensic Sci. Int. 212 (2011) 130-142

[22] C. Champod, C. Lennard, P. Margot and M. Stoilovic, Fingerprints and other ridge skin impression, CRC Press LLC, Florida, 2004, pp. 138-145

[23] D. A. Wilkinson and A. H. Misner, A comparison of thenoyl europium chelate with Ardrox and Rhodamine 6G of cyanoacrylaye fingerprints, CPCR, Technical report TR-08-94, (1994), [Online]

[24] B. Valeur, Effect of polarity on fluorescence emission. Polarity probes, in: Wiley-VCH Verlag GmbH, Molecular Fluorescence: Principles and Applications, 2001,

[25] P. J. Mankidy, R. Rajagopalan and H. C. Foley, Facile catalytic growth of cyanoacrylate nanofibers, Chemical Communications, (2006) 1139-1141

[26] P. J. Mankidy, R. Rajagopalan and H. C. Foley, Influence of initiators on the growth of poly(ethyl 2-cyanoacrylate) nanofibers, Polymer, 49 (2008) 2235-2242

[27] L. A. Lewis, R. W. I. Smithwick, G. L. Devault, B. Bolinger and S. A. S. Lewis, Processes Involved in the Development of Latent Fingerprints Using the Cyanoacrylate Fuming Method, Journal of Forensic Sciences, 46 (2001) 241-246

[28] S. V. Doiphode, D. H. Reneker and G. G. Chase, Nanofibers and spheres by polymerization of cyanoacrylate monomer, Polymer, 47 (2006) 4328-4332 